UDK: 81’366:81’367.625:811.112.2]::811.163.4*3

Izvorni naučni rad

Primljeno: 30. 9. 2019.

Prihvaćeno za štampu: 13. 1. 2020.

dr. sci. Hatidže Burnić, docent

Univerzitet u Bihaću

Islamski pedagoški fakultet

E-mail: hatidze_b@hotmail.com

\title{
PRIMARNA I SEKUNDARNA MORFOLOŠKA ADAPTACIJA GLAGOLSKIH GERMANIZAMA U BOSANSKOM JEZIKU
}

\section{Sažetak}

Pored velikog broja orijentalnih, latinskih, grčkih $i$ drugih stranih riječi $i$ izraza, značajno mjesto u bosanskom jeziku zauzimaju posudenice iz njemačkog jezika. One se u lingvističkoj literaturi nazivaju „germanizmi“.

U ovom radu germanizmi se posmatraju sa stajališta interferencije. Riječ koja se posuduje postaje model koji u jeziku primatelja dobiva svoju repliku. Replika se mora prilagoditi jezičkom sistemu u koji ulazi. Ona se prilagođava na različitim jezičkim razinama.

Polazeći od prethodno navedene konstatacije, glavni cilj ovog rada je prikazati prilagođavanje glagolskih germanizama na morfološkoj razini kako u primarnoj tako i u sekundarnoj fazi.

Ključne riječi: posudenice, germanizmi, morfološka adaptacija glagola.

\section{Uvodni dio rada}

Pri primanju leksema iz jezika davaoca u jezik primaoca, u našem slučaju iz njemačkog jezika u bosanski jezik, događaju se određene promjene na različitim razinama.

Bez obzira na razine, sveukupne promjene mogu se globalno podijeliti u dvije skupine: primarne $i$ sekundarne. Prema tome, razlikujemo primarnu i sekundarnu adaptaciju. 
Analogno tome, razlikujemo prave i poluprave germanizme za koje koristimo i nazive primarni i sekundarni germanizmi određeni prema adaptacijskoj fazi, primarnoj ili sekundarnoj.

Primarna adaptacija hronološki prethodi sekundarnoj, a promjene do kojih dolazi su različite. Smatramo da sam termin ,sekundarna adaptacija“ jasno govori o statusu replike. Iako je njen osnovni oblik formiran i integriran u bosanski jezik, njen cijeli proces adaptacije nije završen. Prva faza je završena i promjene se obično više ne vrše na stranom elementu germanizma, odnosno osnovi. No, domaći elementi koji su dodavani kako bi se replika formirala stalno su izloženi promjenama. Dakle, replika ulazi u sekundarnu fazu adaptacije i nastavlja se adaptacijski proces. Promjene se ne vrše više na samoj osnovi, nego se dodavanjem, oduzimanjem ili zamjenom bosanskih elemenata tvore nove riječi.

Prema tome, pod primarnom fazom podrazumijevamo adaptacijski proces, a pod sekundarnom fazom tvorbeni proces, koji obuhvata sve promjene koje nastaju na adaptiranoj replici (primarnoj replici), a to obuhvata i tvorbenu aktivnost germanizama.

Sekundarnu fazu u užem smislu dalje dijelimo na tercijarnu, kvartarnu i kvintarnu fazu ovisno o statusu tvorenice koja je poslužila kao model u tvorbenom procesu.

U primarne germanizme ubrajamo samo lekseme nastale prema uzoru njemačkog modela, a sekundarnim germanizmima smatramo sve izvedenice motivirane pravim germanizmima. To su germanizmi čiji je oblik izmijenjen te ih razvrstavamo prema načinu izmjene oblika $\mathrm{i}$ dijelimo na preoblikovani dodavanjem završetka, oduzimanjem završetka i zamjenom završetka. 
Sekundarni germanizmi su nastali unutarjezičkom tvorbom motivirani pravim germanizmima. Prema tome, smatramo ih tvorenicama i njihov status određuje faza u kojoj su tvoreni pa ih dijelimo na tercijarne, kvartarne i kvintarne germanizme.

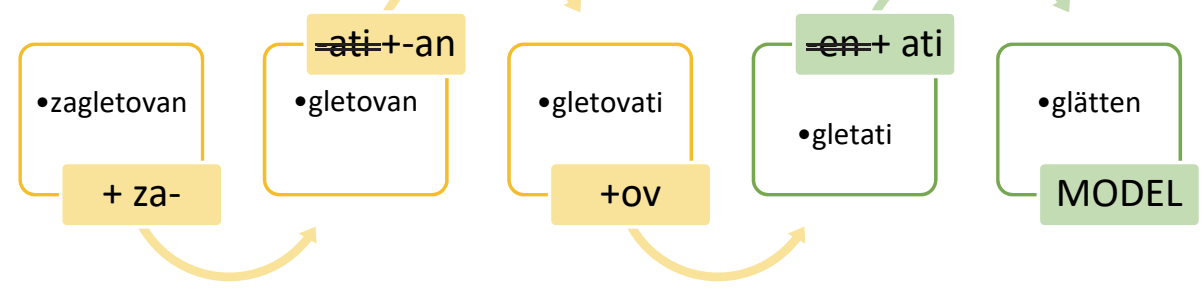

Cijeli put bi se mogu ovako rekonstruisati:

\section{zagletovan $\leftarrow$ gletovan $\leftarrow$ gletovati $\leftarrow$ gletati $\leftarrow$ glätten}

1. U primarnoj fazi posuđen je primarni model glätten i adaptiran zamjenom završetka u primarnu repliku gletati: gletati $\leftarrow$ glätten.

2. U sekundarnoj fazi primarna replika postaje (sekundarni) model, izveden je drugi oblik glagola, tj. glagolska tvorenica koja čini sekundarnu repliku: gletovati $\leftarrow$ gletati.

3. U tercijarnoj fazi sekundarna replika postaje tercijarni model, dodavanjem sufiksa za tvorbu pridjeva te se izvodi tercijarna replika - pridjevska tvorenica gletovan $\leftarrow$ gletovati.

4. U kvartarnoj fazi tercijarna replika postaje kvartarni model i dodavanjem prefiksa $z a$ - izvodi se kvartarna replika - drugi oblik pridjevske tvorenice zagletovan $\leftarrow$ gletovan.

Tvorenica zagletovan postaje kvintarni model i proces ostaje otvoren za eventualnu tvorbu novih riječi na osnovu bilo koje replike. (npr. gletmasa, gleter, gleterleptir, gletanje, gletovanje...)

U ovom radu ćemo prikazati rezultate transmorfmizacije glagolskih germanizama na korpusu od 80 glagola. Uvrstili smo glagolske germanizme adaptirane u primarnoj fazi (24 glagola) i glagolske tvorenice (56 glagola) nastale sufiksacijom i prefiksacijom $u$ sekundarnoj fazi. U prvu grupu spadaju preuzeti glagoli adaptirani 
prema uzoru njemačkih glagola, a druga grupa obuhvata glagolske tvorenice motivirane integriranim germanizmima bez obzira kojoj vrsti riječi pripadale. U našem korpusu ${ }^{1}$ to su većinom adaptirani glagolski germanizmi. Od adaptiranih glagolskih germanizama je tvoreno 35 glagolskih tvorenica, od imeničkih germanizama je tvoreno 20 glagolskih tvorenica $\mathrm{i}$ od jedne njemačke fraze je tvorena jedna glagolska tvorenica. To je ukupno 56 glagola što znači da je broj glagolske leksike skoro tri puta povećan u sekundarnoj fazi.

\section{Morfološka adaptacija germanizama u primarnoj fazi}

Komparirajući glagolsku morfologiju bosanskih i njemačkih sistema uočili smo da u oba jezika osnovne oblike glagola karakterizira infinitivni nastavak. U njemačkom jeziku to su nastavci -en i $-n$, a u bosanskom je karakterističan infinitivni nastavak - $t i$ koji se oblikuje infinitivnim formantima $-a$, -ova, -ira $-i s a .^{2}$

Bez obzira na to da li se radi o glagolskim germanizmima ili glagolskim tvorenicama njemački model se prilagođava na isti način kao i ostale vrste riječi, tj. oduzimanjem i dodavanjem osnovnom dijelu njemačke transfonemizirane replike, te se klasificira $\mathrm{u}$ jedno od slijedećih kategorija: postupak dodavanja, oduzimanja ili zamjene.

Analizirajući razliku između primarnih i sekundarnih glagola, zaključili smo da se osnovni oblici glagolskih germanizama uvijek formiraju zamjenom njemačkih završetaka -en sa bosanskim -ati, a da se glagolske tvorenice izvode na način tvorbe domaćih glagola $u$ bosanskom jeziku, tj. dodavanjem bosanskih gramatičkih morfema (karakteristični za tvorbu glagola) na korijenski morfem neke riječi. Završeci germanizama u našem korpusu glagola su -ovati, -ati $i$-iti.

\footnotetext{
1 Korpus od ukupno 1412 germanizama sastavljen za potrebe moje doktorske disertacije Morfološka adaptacija frekventnih germanizama u medijima $i$ njihova zastupljenost u rječnicima bosanskog jezika poslužio je kao baza za analizu morfološke adaptacije glagolskih germanizama.

${ }^{2}$ Infinitivni formanti pružaju mogućnost alternativnog upotrebljavanja, što je u našem korpusu česta pojava.
} 


\section{Postupak zamjene}

Naša analiza je pokazala da su svi njemački glagoli koji su preuzeti kao modeli prošli isti proces, zamjenu završetaka. Osnova njemačkog glagola je preuzeta, a završetak je zamijenjen infinitivnim nastavkom bosanskog jezika nakon čega potpuno adaptirani glagol (primarna replika) potpada pod konjugaciju bosanskog jezičkog sistema i postaje sekundarni model koji služi za tvorbu drugih oblika glagola i drugih vrsta riječi.

Svi glagoli našeg korpusa koji imaju stepen primarnih replika, čiji su modeli njemački glagoli mijenjaju njemački nastavak sa infinitivnim nastavkom -ati: U korpusu su pronađeni slijedeći glagoli: bajcati, blajhati, blinkati, cvikati, dihtovati, dunstati, dinstati, filati, filcati, flaširati, frezati, fruštikati, frištikati, gletati, hajcati, heftati, hoblati, kipati, šlajfati, štekati, štopati.

Neki glagoli završavaju na nastavak $-i r a t i^{3}$, što se često svodi na infinitivni nastavak -ieren u njemačkom jeziku. U našem korpusu smo pronašli jedan primjer glagolskog germanizma s tim nastavkom faschieren (> faširati)

\section{Postupak dodavanja}

Ovim načinom se rijetko preuzimaju glagolski germanizmi. Pravilo je da se od njemačkog modela tvori ista vrsta riječi u jeziku primaocu, $u$ ovom slučaju bosanskom jeziku. Ipak postoji mogućnost prelaska u drugu vrstu riječi tako da dolazi do transkategorizacije. U našem korpusu pronašli smo jedan germanizam koji odskače od pravila. Glagol persirati formiran je na osnovu modela njemačke fraze per Sie. Glagol persieren ne postoji u njemačkom jeziku, tako da nije mogao poslužiti kao glagol. Tvoren je dodavanjem bosanskog završetka-irati. Radi se o jednom izuzetku formiranja glagola ovim načinom (persieren $<$ per sie).

\footnotetext{
${ }^{3}$ Petar Skok u svom rječniku Etimologijski rječnik hrvatskoga ili srpskoga jezika navodi da je složeni sufiks hibrid sastavljen od njemačkog formanta -ier (koji je adaptiran $\mathrm{u}-i r$ ), formanta $-a$ i nastavka $-t i$.
} 


\section{Morfološka adaptacija germanizama u sekundarnoj fazi}

Svi glagoli koji su nastali u sekundarnoj, tercijarnoj i drugim fazama, formiraju se strategijom dodavanja. Ovdje treba naglasiti da su to uvijek tvorenice koje su nastale nakon završenog primarnog procesa. U našem korpusu bilježimo glagolske tvorenice nastale na osnovu imeničkih i glagolskih germanizama. One podliježu istim pravilima tvorbe glagola u bosanskom jeziku koja može biti prefiksalna, sufiksalna i prefiksalnosufiksalna. ${ }^{4}$

Glagolske tvorenice motivirane integriranim glagolskim germanizmima se izvode dodavanjem bosanskih prefiksa na već sufiksirane glagolske germanizme (stopati > uštopati) i pripadaju svi istoj kategoriji: postupku dodavanja.

Glagolske tvorenice nastale na osnovu imeničkih germanizama se tvore sufiksacijom. Imeničkoj osnovi se na dva načina mogu dodati sufiksi. Ukoliko je germanizam nepreoblikovanog oblika, tj. bez dodatka bosanskog sufiksa kao npr. flek (Fleck) nema potrebe za oduzimanjem prije sufiksacije. Ovaj način također ubrajamo u kategoriju postupak dodavanja.

Ako je izvršeno preoblikovanje osnovnog oblika pri formiranju imeničkog germanizma kao npr. bauštela (Baustelle) dolazi do zamjene, oduzima se njemački završetak i dodaje se bosanski sufiks za tvorbu glagola (bauštela > bauštelati). Ovaj način sufiksacije ubrajamo u kategoriju postupak zamjenom.

\section{Postupak dodavanja}

Ovoj kategoriji pripadaju glagoli tvoreni prefiksacijom, s obzirom da se radi o dodavanju na osnovni oblik germanizma, u ovom slučaju je to glagolski germanizam koji postaje sekundarni model za tvorbu sekundarnih glagola, odnosno glagolskih tvorenica motiviranim glagolskim germanizmima.

Tvorbeni način ,,prefiksaciju“ smatramo strategijom koju ubrajamo u kategoriju ,postupak dodavanja modelu““.

\footnotetext{
${ }^{4}$ Memnuna Hasanica (2009): Akcionalnost i tvorbeni modeli glagola u njemačkom $i$ b,h,s jeziku, str. 64 .
} 
U našem korpusu bilježimo slijedeće prefiksacije:

$>$ Prefiks $u$ -

ubajcati $\leftarrow$ bajcati $\leftarrow$ beizen

ubajcovati $\leftarrow$ bajcovati $\leftarrow$ bajcati $\leftarrow$ beizen

uglancati $\leftarrow$ glancati $\leftarrow$ glanc $\leftarrow$ Glanz

uflekati $\leftarrow$ flekati $\leftarrow$ flek $\leftarrow$ Fleck

uštekati $\leftarrow$ štekati $\leftarrow$ stecken

uštopati $\leftarrow$ štopati $\leftarrow$ stopfen

$>$ Prefiks $i z-$

izblajhati $\leftarrow$ blajhati $\leftarrow$ bleichen

izdinstati $\leftarrow$ dinstati $\leftarrow$ dünsten

izdunstatii $\leftarrow$ dunstati $\leftarrow$ dünsten

isfrezati $\leftarrow$ frezati $\leftarrow$ freza $\leftarrow$ Fräse

izhoblati $\leftarrow$ hoblati $\leftarrow$ hobln

izglancati $\leftarrow$ glancati $\leftarrow$ glanc $\leftarrow$ Glanz

izluftati $\leftarrow$ luftati $\leftarrow$ luft $\leftarrow$ Luft

izdrukati $\leftarrow$ drukati $\leftarrow$ druker $\leftarrow$ Drucker

Prefiks is-, iš-, (nastali pod utjecajem glasovne promjene) $)^{5}$

iskipati $\longleftarrow$ kipati $\leftarrow$ kippen

isflekati $\leftarrow$ flekati $\leftarrow$ flek $\leftarrow$ Fleck

ištekati $\leftarrow$ štekati $\leftarrow$ stecken

${ }^{5}$ Prefiksi iz-, (...) u susretu s glasovima kojima se, u skladu s njihovim artikulacijskoakustičkim svojstvima, moraju prilagoditi, dobivaju alternirane oblike. Tako se izostvaruje kao iz- (izbaciti), kao iž- (...), kao iš- iščistiti.) i kao i- (...).; Silić, Pranjković, (2005) Gramatika hrvatskoga jezika za gimnazije $i$ visoka učilišta, Školska knjiga, Zagreb, str. 147. U bosanskom jeziku takvi primjeri su: ishitriti (iz+hitriti), iskopati (iz+kopati), iščupati (preko isčupati od izčupati), S. Halilović, Pravopis bosanskoga jezika, Slavistički komitet, 2017. Sarajevo, str. 133-134. 
$>$ Prefiks z-

zglajzati $\leftarrow$ glajzati $\leftarrow$ gleisen

zdinstati $\leftarrow$ dinstati $\leftarrow$ dünsten

zdunstati $\leftarrow$ dunstati $\leftarrow$ dünsten

zglancati $\leftarrow$ glancati $\leftarrow$ glanc $\leftarrow$ Glanz

$>$ Prefiks $z a-$

zaheftati $\leftarrow$ heftati $\leftarrow$ heften

zaglancati $\leftarrow$ glancati $\leftarrow$ glanc $\longleftarrow$ Glanz

zagletati $\leftarrow$ gletati $\leftarrow$ glätten

$>$ Prefiks na-

nafilati $\leftarrow$ filati $\leftarrow$ füllen

naglancati $\leftarrow$ glancati $\leftarrow$ glanc $\leftarrow$ Glanz

nahajcati $\leftarrow$ hajcati $\leftarrow$ heizen

$>$ Prefiks 0 -

oblajhati $\leftarrow$ blajhati $\leftarrow$ bleichen

ocvikati $\leftarrow$ cvikati $\leftarrow$ zwicken

$>$ Prefiks pre-

precvikati $\leftarrow$ cvikati $\leftarrow$ zwicken

$>$ Prefiks pro-

prodinstati $\leftarrow$ dinstati $\leftarrow$ dünsten

Primjera dodavanja na imenički germanizam nema mnogo. Razlikuju se od glagolskih germanizama u tome što se imenici dodaju sufiksi potrebni za tvorbu glagola. Naš korpus bilježi samo dva glagola: flekati i glancati. S obzirom da oni imaju status sekundarnih germanizama i postaju tercijarni modeli, konstatiramo da su prefiksacijom dobiveni glagoli uflekati, isflekati, uglancati, izglancati, naglancati postali tercijarne replike.

uflekati, isflekati $\leftarrow$ flekati $(<$ flek $<$ der Fleck)

uglancati, naglancati, izglancati $\leftarrow$ glancati $(<$ glanc $<$ der Glanc $)$ 


\section{Postupak zamjene}

Glagolske tvorenice nastale na osnovu preoblikovanih imeničkih germanizama se tvore sufiksacijom na način da se imeničkoj osnovi oduzima njemački završetak i dodaje se bosanski sufiks za tvorbu glagola. U našem korpusu bilježimo slijedeće sufiksacije:

Primjeri sa -ati su: bauštelati ( $<$ bauštela $<$ die Baustelle), brenati ( $<$ brenšer $<$ die Brennschere), drukati $(<$ druker $<$ der Drucker).

Primjeri sa -ovati su: bauštelovati ( $<$ bauštela $<$ die Baustelle), brenovati $(<$ brenšer $<$ die Brennschere), futrovati $(<$ futer $>$ das Futter).

Izdvajamo samo jednu glagolsku tvorenicu koja je nastavila proces $\mathrm{i}$ postala produktivna u tercijarnoj fazi, to je glagol drukati na osnovu kojeg je izveden prefiksirani glagol izdrukati: izdrukati $\leftarrow$ drukati $(<$ druker $<$ der Drucker $)$

\section{Adaptacija glagolskog vida}

Glagolski vid je vrlo bitna morfološka kategorija kod analize adaptacije glagola jer se bosanski i njemački glagolski sistem u izražavanju glagolskog vida znatno razlikuju. Za razliku od bosanskih glagola, većina glagola u njemačkom jeziku aspektno je neoznačena i glagolski vid se izražava različitim morfosintaktičkim i leksičkim sredstvima. Njihove se replike $\mathrm{u}$ toku adaptacije mogu svrstati u tri skupine: nesvršeni glagoli (imperfektivni vid), svršeni glagoli (perfektivni vid) i dvovidni glagoli. S obzirom na tu razliku, glagoli se gotovo isključivo adaptiraju u bosanski jezik kao nesvršeni glagoli i nadalje se u sekundarnoj adaptaciji formiraju oblici svršenih glagola. Naš korpus obuhvata slijedeće primjere nesvršenih glagola: bajcati, blajhati, blinkati, cvikati, dihtovati, dunstati, dinstati, filati, filcati, flaširati, frezati, fruštikati, frištikati, gletati, hajcati, heftati, hoblati, kipati, šlajfati, štekati, štopati.

Od njih su tvoreni: upajcati, izblajhati, oblajhati, ocvikati, precvikati, izdinstati, zdinstati, prodinstati, nafilati, isfrezati, zagletati, nahajcati, zaheftati, iskipati, uštekati, uštopati.... 


\section{Zaključak}

Sveukupne promjene mogu se globalno podijeliti u dvije skupine: primarne $i$-sekundarne. U fazi primarne adaptacije njemačka posuđenica se prilagođava sistemu bosanskog jezika, dok u fazi sekundarne adaptacije ona postaje podložna promjenama na različitim razinama kao i bilo koja druga bosanska riječ.

Primarna adaptacija je jasno određena. Ona počinje ulaskom njemačkog modela u bosanski jezički sistem i završava formiranjem replike.

Sekundarna adaptacija je jasna samo što se tiče postanka. Završetak se ne može odrediti jer svaka replika, bilo da je primarna ili sekundarna može biti produktivna i razvijati se neograničeno. Te promjene su uvijek vezane samo za pravila bosanskog jezičkog sistema i nemaju kraja, tako da proces teoretski nema završetka.

Njemački dio ostaje uvijek strani dio, iako ga uvrštavamo u naš govor i ubrajamo u svoje leksičko blago. Jedno ostaje jasno - osnov je njemački model koji dalje modelira i ostaje na putu sekundarnog adaptacijskog procesa.

Rezultati adaptacije glagola su pokazali da je dva puta manji broj primarnih glagolskih germanizama u odnosu na sekundarne glagolske tvorenice. U korpusu smo zabilježili 24 glagolska germanizma, a 56 tvorenica nastalih od integriranih germanizama. Bez obzira da li se radilo o primarnim ili sekundarnim germanizmima, mi smo analizom ustanovili da se odvija uvijek isti proces. Dakle, ukoliko je njemački glagol poslužio kao model dolazi do postupka zamjene njemačkog sa bosanskim završetkom. Ukoliko je model druga vrsta riječi ili integrirani germanizam, dolazi do dodavanja bosanskog nastavka na osnov njemačkog germanizma. Naši rezultati su pokazali da se glagolski germanizmi uglavnom formiraju prema uzoru na njemačke glagole, što je slučaj u 23 od 24 primjera našeg korpusa. Glagol $<$ persirati odskače od pravila, on je formiran na osnovu modela njemačke fraze per Sie. Tvoren je dodavanjem bosanskog završetka irati. Radi se o jednom izuzetku formiranja glagola ovim načinom.

Rezimiramo da s morfološkog aspekta definitivno nema razlike između prve i ostalih replika (primarne i sekundarne). Model odnosno njemački leksički osnov nakon primarne adaptacije se izdvaja i modelira te 
adaptira $\mathrm{u}$ drugim kategorijama. Također sa aspekta statusa riječi $\mathrm{u}$ bosanskom jeziku, tvrdimo da nema dilema oko glagola filati, filovati, nafilovati... da li pripadaju germanizmima. ${ }^{6}$

Završno možemo konstatirati da su svi adaptaptirani glagolski germanizmi našeg korpusa nakon primarne adaptacije nastavili svoj razvoj u sekundarnoj fazi. Prema tome, novotvoreni glagoli motivirani primarnom replikom su jasna potvrda adaptiranosti germanizama, a njihova produktivnost $\mathrm{u}$ bosanskom jezičkom sistemu je najbolji pokazatelj integriranosti germanizama. Smatramo da tvorenice motivirane replikom imaju isti status kao i replike ako ih posmatramo etimološki i da ih ne možemo smatrati domaćim riječima iako se $u$ sekundarnoj fazi razvijaju u bosanskom jeziku pod utjecajem bosanskog jezičkog sistema.

\section{Literatura}

1. Burnić, Hatidže (2015) Morfološka adaptacija frekventnih germanizama u medijima i njihova zastupljenost u rječnicima bosanskog jezika, doktorska teza, Mostar.

2. Čedić, Ibrahim et al. (2007) Rječnik bosanskog jezika. Institut za jezik, Sarajevo.

3. Filipović, Rudolf (1986) Teorija jezika u kontaktu. JAZU- Školska knjiga, Zagreb.

4. Filipović, Rudolf et al. (1999) Transmorfemizacija modela šest europskih jezika u hrvatskom. Filologija 33, Zagreb str. 15-54.

5. Grotzky, Johannes (1978) Morphologische Adaptationen deutscher Lehnwörter im Serbokroatischen, Beiträge zur Kenntnis Südeuropas und des Nahen Orients, Bd. 26, München.

6. Halilović, S. (2017) Pravopis bosanskoga jezika, Slavistički komitet, Sarajevo.

7. Hasanica, Memnuna (2009) Akcionalnost i tvorbeni modeli glagola u njemačkom i b,h,s jeziku. Pedagoški fakultet Univerziteta u Zenici, Zenica.

${ }^{6}$ U rječniku Halilovića i ostalih nema nikako natuknice filati koja je primarni germanizam. Pod natuknicom fil (tvorenicom) stoji etimološki podatkak (njem.) a sve ostale tvorenice (filovan, filovati) ostaju bez ukazivanja na izvorni jezik. U rječniku Čedića germanizam fil nije evidentiran u nijednom obliku. 
8. Jahić, Dževad (2010, 2011, 2012, 2014) Rječnik bosanskog jezika, Sejtarija, Sarajevo.

9. Silić, J., Pranjković, I. (2005) Gramatika hrvatskoga jezika za gimnazije i visoka učilišta, Školska knjiga, Zagreb.

10. Skok, Petar (1971) Etimologijski rječnik hrvatskoga ili srpskoga jezika. JAZU, Zagreb.

11. Štebih, Barbara (2008) Morfološka adaptacije posuđenica. Institut za hrvatski jezik i jezikoslovlje, Zagreb, str. 243-259. 


\title{
PRIMARY AND SECONDARY MORPHOLOGICAL ADAPTATION OF VERBAL GERMANISMS IN THE BOSNIAN LANGUAGE
}

\author{
PhD Hatidže Burnić, Islamic Faculty of Pedagogy \\ University of Bihać
}

E-mail: hatidze_b@hotmail.com

Abstract

In addition to a large number of Oriental, Latin, Greek and other foreign words and expressions, borrowings from the German language take an important place in the Bosnian language. They are referred to in the linguistic literature as "Germanisms".

In this paper, Germanisms are viewed from the standpoint of interference. The borrowed word becomes a model that receives its replica in the recipient's language. The replica must adapt to the language system it enters. It adapts to different language levels.

Starting from the above statement, the main aim of this paper is to present an adaptation of verbal Germanisms at the morphological level in both the primary and secondary stages.

Keywords: loanwords, Germanisms, morphological adaptation of verbs. 


$$
\begin{aligned}
& \text { الدكتور المحاضر سيدة خديجة بورنيتش } \\
& \text { جامعة بيهاتش إنش } \\
& \text { كلية التربية الإسلامية }
\end{aligned}
$$

\section{التكيّف الصرفي الأصلي والفرعي للأفعال ألمانية الأصل في اللغة البوسنية}

\section{الملخص}

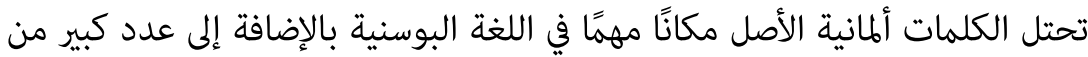

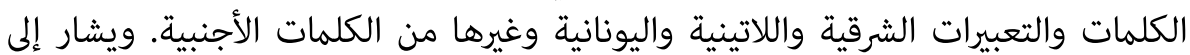

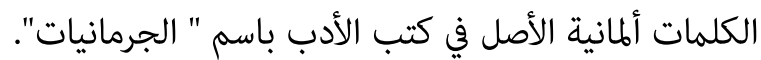

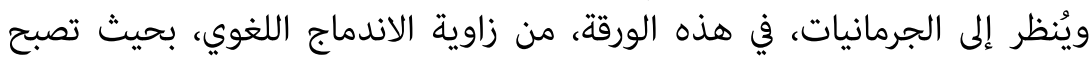

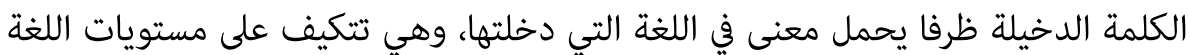
المتنوعة.

انطلاقا من هذه الحقيقة فإن الهدف الرئيسي من هذه الورقة هو عرض تكيّفالأفعال

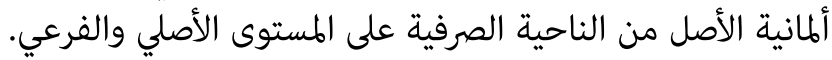
الكلمات المفتاحية: الكلمات الدخيلة، الجرمانيات، التكيّف الصئف الصرفي للأفعال. 